\title{
New tools to screen wild peanut species for aflatoxin accumulation and genetic fingerprinting
}

Renee S. Arias ${ }^{1 *}$, Victor S. Sobolev ${ }^{1}$, Alicia N. Massa', Valerie A. Orner ${ }^{1}$, Travis E. Walk', Linda L. Ballard², Sheron A. Simpson ${ }^{2}$, Naveen Puppala ${ }^{3}$, Brian E. Scheffler ${ }^{2}$, Francisco de Blas ${ }^{4}$ and Guillermo J. Seijo ${ }^{4,5}$

\begin{abstract}
Background: Aflatoxin contamination in peanut seeds is still a serious problem for the industry and human health. No stable aflatoxin resistant cultivars have yet been produced, and given the narrow genetic background of cultivated peanuts, wild species became an important source of genetic diversity. Wild peanut seeds, however, are not abundant, thus, an effective method of screening for aflatoxin accumulation using minimal seeds is highly desirable. In addition, keeping record of genetic fingerprinting of each accession would be very useful for breeding programs and for the identification of accessions within germplasm collections.

Results: In this study, we report a method of screening for aflatoxin accumulation that is applicable to the small-size seeds of wild peanuts, increases the reliability by testing seed viability, and records the genetic fingerprinting of the samples. Aflatoxin levels observed among 20 wild peanut species varied from zero to $19000 \mathrm{ng} \cdot \mathrm{g}^{-1}$ and $155 \mathrm{ng} \cdot \mathrm{g}^{-1}$ of aflatoxin $B_{1}$ and $B_{2}$, respectively. We report the screening of 373 molecular markers, including 288 novel SSRs, tested on 20 wild peanut species. Multivariate analysis by Neighbor-Joining, Principal Component Analysis and 3D-Principal Coordinate Analysis using 134 (36\%) transferable markers, in general grouped the samples according to their reported genomes. The best 88 markers, those with high fluorescence, good scorability and transferability, are reported with BLAST results. High quality markers (total 98) that discriminated genomes are reported. A high quality marker with UPIC score 16 (16 out of 20 species discriminated) had significant hits on BLAST2GO to a pentatricopeptide-repeat protein, another marker with score 5 had hits on UDP-D-apiose synthase, and a third one with score 12 had BLASTn hits on La-RP 1B protein. Together, these three markers discriminated all 20 species tested.
\end{abstract}

Conclusions: This study provides a reliable method to screen wild species of peanut for aflatoxin resistance using minimal seeds. In addition we report 288 new SSRs for peanut, and a cost-effective combination of markers sufficient to discriminate all 20 species tested. These tools can be used for the systematic search of aflatoxin resistant germplasm keeping record of the genetic fingerprinting of the accessions tested for breeding purpose.

Keywords: Fingerprinting, groundnut, peanut, molecular markers, aflatoxin, Arachis, Aspergillus flavus

\section{Background}

Presence of aflatoxins in peanut meal caused massive mortality of poultry almost 60 years ago [1]. Since then, significant effort was made to obtain peanut varieties with resistance to the accumulation of aflatoxins [2-6]; and, though progress has been made, there are no cultivated

\footnotetext{
*Correspondence: renee.arias@ars.usda.gov

${ }^{1}$ USDA-ARS-NPRL, National Peanut Research Laboratory (NPRL), 1011

Forrester Dr. S.E, Dawson, GA 39842, USA

Full list of author information is available at the end of the article
}

peanuts with stable resistance to these mycotoxins [6]. Aflatoxins are secondary metabolites produced mainly by the fungi Aspergillus flavus Link ex Fries and Aspergillus parasiticus Speare; are highly carcinogenic compounds [7] and accumulate in seeds of many crops. These polyketide-derived mycotoxins cause acute hepatotoxicity and immunosuppression $[8,9]$ as well as human and animal deaths by aflatoxicosis (Azziz-Baumgartner et al. 2005). In the United States, aflatoxins cost farmers and the peanut industry millions in losses each year $[10,11]$, 
whereas losses due to aflatoxin contamination of peanut exports worldwide account for as much as $\$ 450$ million [12].

Cultivated peanuts have a narrow genetic background [13], due to multiple factors, e.g., biology, habitat, origin, ploidy, section, as summarized by Mallikarjuna et al. (2011) [14]. This is evident when using molecular markers, which normally show low levels of polymorphism [15-17] in peanut. Thus, for decades, researchers have recognized the need to broaden the genetic background of peanut by incorporating wild species germplasm [18-20], and wild relatives of the cultigen $A$. hypogaea $\mathrm{L}$. have been recognized as an important source of genes for resistance to biotic and abiotic stresses [21]. The peanut collection at USDA National Plant Germplasm System consists of 9,321 accessions of cultivated peanut (Arachis hypogaea) and 655 accessions from 66 wild Arachis species; most accessions (44\%) were collected from South America [22] in a multinational effort that involved many expeditions to the center of origin $[19,20$, 23]. The peanut germplasm collection in Griffin is composed of accessions collected from 102 countries.

The genetics of aflatoxin resistance is complex, involving pre-harvest response, post-harvest, genotype $\mathrm{x}$ environment interaction, and host-pathogen interactions [24]; however, the use of in vitro seed colonization (IVSC) provides useful information and has resulted in six new sources of resistance being identified and confirmed by other researchers [24]. The IVSC method was used to identify two interesting Arachis species with low accumulation of aflatoxin, A. cardenasii Krapovickas and Gregory and A. duranensis Krapovickas \& Gregory, and they were targeted for introgression into A. hypogaea $\mathrm{L}$. [6]. Since wild peanut seeds are not readily available, screenings for aflatoxin resistance trait should use minimal seeds. Given the large variability of aflatoxin accumulation in seeds, even under controlled conditions, experiments usually require hundred grams of seeds or more and large planting areas $[25,26]$. Though screening with much smaller amounts, $5 \mathrm{~g}$ of seed per replicate have been reported [6].

No general screening of phenotypic and genetic fingerprinting characteristics has been done of the germplasm collection of wild peanut species, particularly in relation to aflatoxin accumulation. At the NPRL we have developed a method to screen for aflatoxin accumulation by inoculating few seeds with an aflatoxigenic Aspergillus and analyzing each half cotyledon using ultra performance liquid chromatography (UPLC) [27-29]. Here we developed a method adapted to the small size of wild peanut seeds, performing single seed analysis and added reliability to the results by testing the viability of each seed, while keeping record of each accession using novel SSR markers. We provide a final useful set of tools not only for the cost-effective screening of the germplasm collection, but also generating a genotypic and phenotypic database that can be used by peanut breeders.

\section{Methods \\ Microsatellite development}

DNA of Arachis hypogaea subsp. fastigiata var. fastigiata cv. New Mexico Valencia C peanut seeds (provided by Dr. Naveen Puppala) was extracted using DNeasy Plant Maxi Kit (Qiagen, Valencia, CA) and SSR-enriched libraries were generated [30]. Briefly, DNA was digested with restriction enzymes AluI, HaeIII, DraI, and RsaI (New England Biolabs, Ipswich, MA), then the blunt-end DNA fragments were A-tailed with Taq-DNA Polymerase (Promega, Madison, WI) and ligated to a linker made from oligos SSRLIBF3: 5'- CGGGAGAGCAAGGAAGGAGT-3' and SSRLIBR3 5'Phos-CTCCTTCCTTGCTCTCTCCCGAAA A-3' [30]. Ligated fragments were amplified by PCR, and the product was hybridized to groups 2 and 3 of biotinylated oligo repeats [31]. Hybridizations were followed by an extension step of $10 \mathrm{~min}$ at $68^{\circ} \mathrm{C}$ as indicated in Hayden et al. [32] in the presence of High Fidelity Taq Polymerase (Invitrogen, Carlsbad, CA). Sequences containing repeats were captured using streptavidin-coated magnetic beads M-270 (Invitrogen, Carlsbad, CA) in a Labquake tube shaker/rotator (Barnstead/Thermoline, Dubuque, IA) at $22^{\circ}$ $\mathrm{C}$ for $1 \mathrm{~h}$ [33]. Elution of the DNA from the biotinylated oligos was done with $60 \mu \mathrm{l}$ MilliQ water and the eluate was PCR amplified for 10 cycles as indicated for the ligation step (Techen et al., 2010). PCR products were sequenced by pyrosequencing in a Roche 454-GS Junior (Roche, Indianapolis, IN). Sequences were assembled with Roche 454 gsAssembler version 2.0 (Roche, Branford, CT). Repeats were searched using SSRFinder [34] and primers were designed using Primer3 [35] for a melting temperature of 63 $\pm 1^{\circ} \mathrm{C}$, and 5 base pairs (bp) as maximum overlapping with repeats. DNA sequences containing repeats were BLAST to the genomes of Arachis ipaënsis Krapovickas \& Gregory and Arachis duranensis Krapovickas \& Gregory [36] and to gene ontology (BLAST2GO ${ }^{\circ}$ [37]. Results of BLAST to $A$. duranensis and $A$. ipaënsis are shown in Additional file 1: Table S1, and results of BLAST2GO are listed in Additional file 2: Table S2.

\section{Fingerprinting of 20 wild species of peanuts from the germplasm collection}

The first 20 wild species of peanuts alphabetically listed in the bank of germplasm were chosen for the experiments, seeds of one accession per species, Table 1, were obtained from the Plant Genetic Resources Conservation Unit (PGRCU), Griffin, GA. Twenty was considered a manageable number of accessions to develop a screening method, though the goal is to screen the rest of the collection. Genomic DNA was extracted from seeds of 20 wild peanut species and the control cultivar Georgia-11J 
Table 1 Arachis genotypes included in this study

\begin{tabular}{|c|c|c|c|c|c|}
\hline Section and Species & $2 n$ & Genome & PI number & Life cycle & Source \\
\hline \multicolumn{6}{|l|}{ Arachis } \\
\hline Arachis batizocoi Krapov. \& W.C. Gregory & 20 & K & PI 298639 & Perennial or biennial & Bolivia \\
\hline Arachis benensis Krapov., W.C. Gregory \& C.E. Simpson & 20 & $\mathrm{~F}$ & PI 475877 & Annual & Bolivia \\
\hline Arachis cardenasii Krapov. \& W.C. Gregory & 20 & A & PI 475994 & Perennial & Bolivia \\
\hline Arachis correntina (Burkart) Krapov. \& W.C. Gregory & 20 & A & PI 210554 & Perennial & -- \\
\hline Arachis cruziana Krapov., W.C. Gregory \& C.E. Simpson & 20 & K & PI 476003 & Annual & Bolivia \\
\hline Arachis decora Krapov., W.C. Gregory \& Valls & 18 & Unknown & PI 666082 & Annual & Brazil \\
\hline Arachis diogoi Hoehne & 20 & A & PI 276235 & Perennial & Paraguay \\
\hline Arachis duranensis Krapov. \& W.C. Gregory & 20 & A & PI 219823 & Annual & Argentina \\
\hline Arachis glandulifera Stalker & 20 & $\mathrm{D}$ & PI 468343 & Annual & Bolivia \\
\hline Arachis helodes Martius ex Krapov. \& Rigoni & 20 & A & PI 468144 & Perennial & Brazil \\
\hline Arachis ipaënsis Krapov., W.C. Gregory & 20 & B & PI 468322 & Annual & Bolivia \\
\hline Arachis magna Krapov. et al. & 20 & B & PI 598184 & Annual & -- \\
\hline Arachis monticola Krapov. \& Rigoni & 40 & $A B$ & PI 468196 & Annual & Argentina \\
\hline \multicolumn{6}{|l|}{ Erectoides } \\
\hline Arachis benthamii Handro & 20 & $E$ & PI 468162 & Perennial & Brazil \\
\hline Arachis cryptopotamica Krapov. \& W.C. Gregory & 20 & E & PI 468165 & Perennial & Brazil \\
\hline Arachis hermannii Krapov. \& W.C. Gregory & 20 & E & PI 604847 & Perennial & Brazil \\
\hline \multicolumn{6}{|l|}{ Heteranthae } \\
\hline Arachis dardani Krapov. \& W.C. Gregory & 20 & $\mathrm{H}$ & PI 591364 & Annual or biennial & Brazil \\
\hline \multicolumn{6}{|l|}{ Procumbentes } \\
\hline Arachis chiquitana Krapov., W.C. Gregory \& C.E. Simpson & 20 & PR & PI 476006 & Perennial & Bolivia \\
\hline \multicolumn{6}{|l|}{ Rhizomatosae } \\
\hline Arachis burkartii Handro & 20 & R1 & PI 468162 & Perennial & Brazil \\
\hline Arachis glabrata var. hagenbeckii Benth. (Harms ex. Kuntze) F.J. Herm. & 40 & R2 & PI 262839 & Perennial & Paraguay \\
\hline
\end{tabular}

[38], using DNeasy Plant Mini Kit (Qiagen, Valencia, CA). A total of 288 newly developed peanut SSRs (Additional file 1: Table S1), in addition to 92 Insertion/Deletion (InDel) markers [39] and microsatellites reported in the literature [21, 40-44] (Additional file 2: Table S2), formed a list of 373 markers used for fingerprinting. Forward primers were 5 ' tailed with the sequence 5'-CAGTTTTCC CAGTCACGAC-3' [45] and reverse primers were tailed at the 5' end with the sequence 5'-GTTT-3' to promote non-template adenylation [46]. Primer 5'-CAGTTTTCC CAGTCACGAC-3' labeled with 6-carboxy-X-rhodamine (ROX) (IDT-Technologies, Coralville, IA) was used for amplification of 10-ng DNA using Titanium Taq DNA Polymerase (Clontech, Mountain View, CA) as reported before [47]. Fluorescently-labeled PCR fragments were analyzed by capillary electrophoresis on an ABI 3730XL DNA Analyzer and data processed using GeneMapper 4.0 (both from Applied Biosystems, Foster City, CA). Presence of alleles was converted to a binary matrix and Principal Component Analysis (PCA) was performed to identify patterns of genetic relationships using the $R$ package adegenet version 2.0.1 [48] in R version 3.4.0 [49]. Cluster analysis by Neighbor Joining (NJ) and 3D-Principal Coordinate Analysis (3D-PCoA) were calculated using NTSYSpc v. 2.2 (Exeter Software, Setauket, NY). Confidence level of the generated dendrogram was assessed by bootstrap with 5000 re-sampling [50, 51]. Based on transferability, polymorphism and ease to score, data from the best markers were used to calculate their actual discriminating power by running UPIC scripts [52], and to find the most informative combination of markers that can distinguish all the samples tested. UPIC scripts were also used to calculate the heterozygosity of the samples at each of the loci.

\section{Screening of wild peanut species for aflatoxin accumulation and viability}

Long term storage and maturity level at harvest can affect the viability of seeds within the germplasm collection, therefore, each seed tested for aflatoxin accumulation was also screened for viability through germination under in vitro culture conditions. Four peanut seeds of 
each of the 20 wild species of peanut, Table 1, were challenged with Aspergillus flavus (Link) NRRL3357 to quantify aflatoxin accumulation using a previously reported method [27] with some modifications due to the small size of wild peanut seeds. Seeds of peanut cultivar Georgia-11J [38] were used as controls and processed as the wild species. The introduced changes were: a) the use of $1 \%$ sodium hypochlorite solution for disinfection (instead of $2 \%$ ); b) $3 \mathrm{~h}$ imbibition (instead of $2 \mathrm{~h}$ ); c) seeds with testa (skins) were cut in two pieces (cross section) without separating the cotyledons, d) use of only the apical (distal) half for inoculation, e) the inoculum size per half seed was $0.2 \mu \mathrm{L}$ of a freshly made spore suspension in water (3 $\times 10^{5}$ spores $/ \mathrm{mL}$ ) of a 5-7 day-old culture of A. flavus NRRL 3357 grown on potato-dextrose agar (PDA). Water-agar Petri dishes containing the inoculated half seeds were incubated in the dark at $29 \pm 1{ }^{\circ} \mathrm{C}$; after $72 \mathrm{~h}$ incubation each half seed was placed in separate pre-weighed 4 $\mathrm{mL}$ vials and weighed; the weights were recorded, and the seeds were stored at $-80^{\circ} \mathrm{C}$ until chemical analysis (no longer than 3 weeks). To assess the viability of the seeds, the proximal half (containing the embryonic axis) was placed in test tubes $(25 \times 250 \mathrm{~mm})$ containing $18 \mathrm{~mL}$ of Hoagland's No. $2(0.4 \mathrm{~g} / \mathrm{L})(\mathrm{H} 2395$, Millipore-Sigma) and agar $(6 \mathrm{~g} / \mathrm{L})$. Seeds in Hoagland's medium were incubated at $28 \pm 1^{\circ} \mathrm{C}$ in the dark for seven days, and $16 \mathrm{~h} \mathrm{light} / 8 \mathrm{~h}$ dark thereafter. Four seeds per peanut accession were tested for aflatoxin accumulation and viability assessment as germination. Mycelium growth after inoculation, and seed germination were documented by photographs.

\section{Aflatoxin analysis}

Seed halves inoculated with A. flavus were transferred from the $4 \mathrm{~mL}$ vials to $2 \mathrm{~mL}$ reinforced tubes containing six $2.8 \mathrm{~mm}$ ceramic beads (cat \#: 19-649 \& 19-646-3, respectively, Omni International, Kennesaw, GA) and 0.5 $\mathrm{mL}$ methanol; the samples were pulverized for $20 \mathrm{sec}$ at $5.5 \mathrm{~m} / \mathrm{s}$ in a Bead Ruptor 24 homogenizer (Omni International). Using a Pasteur pipette, the liquid was transferred to another Pasteur pipette previously fitted with a glass fiber plug and $70 \mathrm{mg}$ Celite ${ }^{\circ} 545$ (Sigma); the liquid was forced through the pipette column using nitrogen gas and collected into a $700 \mu \mathrm{L}$ Ultra-High Performance Liquid Chomatographer (UPLC) auto sampler vial (part \# 186005221, Waters, Milford, MA). Samples were subjected to aflatoxin analysis using a Waters Acquity UPLC instrument equipped with a matching UPLC H-class Quaternary Solvent Manager, UPLC Sample Manager, UPLC Fluorescent Detector (FLR), and an Acquity UPLC BEH C18 $2.1 \mathrm{~mm}$ x $50 \mathrm{~mm}, 1.7 \mu \mathrm{m}$ column. Water (A), methanol (B), and acetonitrile (C) were used in the following gradient: initial conditions, $64 \% \mathrm{~A} / 23 \% \mathrm{~B} / 13 \% \mathrm{C}$, held for $4 \mathrm{~min}$, changed to $6 \% \mathrm{~A} / 40 \% \mathrm{~B} / 54 \% \mathrm{C}$ in $0.01 \mathrm{~min}$, held for $4 \mathrm{~min}$, changed to initial conditions in $0.01 \mathrm{~min}$, held isocratic for $2 \mathrm{~min}$ before next injection. The flow rate was $0.3 \mathrm{~mL} / \mathrm{min}$. The column was maintained at 40 ${ }^{\circ} \mathrm{C}$ in the system column heater. Concentrations of aflatoxins were determined by reference to peak areas of corresponding commercial standards (calibration curve). The lowest detection limit for aflatoxin $B_{1}$ was $0.10 \mathrm{ng} . \mathrm{g}^{-1}$ and $0.01 \mathrm{ng} . \mathrm{g}^{-1}$ for aflatoxin $\mathrm{B}_{2}$. Statistical tests were performed using the statistical package Sigma Plot v. 12.5 (Systat Software Inc., San Jose, CA).

\section{Results}

\section{Sequencing, SSR isolation and primer design}

High throughput sequencing and assembly of SSR-enriched libraries generated from Valencia peanut resulted in 2,974 contigs and 34,344 singletons; a total of 11,600 SSRs were detected, and 879 unique primer sets were designed. The first 288 markers in that list, a manageable number of primers ( 3 plates of 96 wells), were tested and reported in the present work. A total of 265 sequences containing the 288 SSRs were uploaded to the National Center for Biotechnology Information (NCBI) with GenBank with accession number: KY177179 to KY177444, sequence names in the database match the names of the SSR markers reported here. The frequency of repeat motifs in the 288 microsatellites was $58,161,61,3$ and 5 , for di, tri, tetra, penta, and hexa nucleotide (nt), respectively; whereas the number of repeat units in the microsatellites ranged from 4 to 64 units. Numerous types of repeats were detected; the most abundant repeat motifs were: ATC, AAG, TCG, GA and TTC, though none of them exceeded $9 \%$ of the total number of repeats. Repeat motifs for each primer set, primer sequences, alleles per marker and amplicon sizes are described in Additional file 1: Table S1. Also included in this table are the number of alleles and amplicon sizes for markers obtained using published markers, and the results of BLAST2GO for the sequences. Since the average length of DNA sequences containing markers was 284 bp (Additional file 1: Table S1) and the amplicon sizes ranged from $94-489 \mathrm{bp}$, it is highly likely that marker polymorphisms occurred within the open-reading frames of sequences that had significant hits on BLAST2GO. BLAST results against the genomes of Arachis ipaënsis (Krapovickas \& Gregory) and Arachis duranensis (Krapovickas \& Gregory) indicating chromosome location are shown in Additional file 3: Table S3. A total of 373 markers were used to screen 20 wild species of peanut. From these 373 markers, a total of $193(52 \%)$ were located in the same corresponding chromosomes of A. ipaënsis and A. duranensis. The distribution of these 193 markers showed that all 10 chromosomes were represented by the markers used in this study, with $3 \%$ of the markers on chromosome 8 , to $20 \%$ on chromosome 3 , Fig. 1 . The uneven distribution was apparently related to the small size of chromosome 8 and large size of chromosome 3 in A. duranensis, Fig. 1. Included in the fingerprinting analysis, there were 85 markers, both SSRs and InDels, 


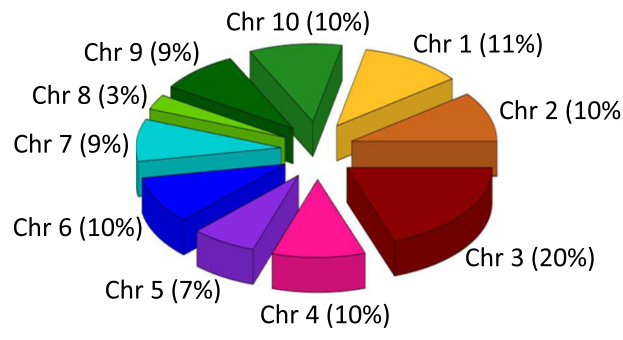

A. duranensis

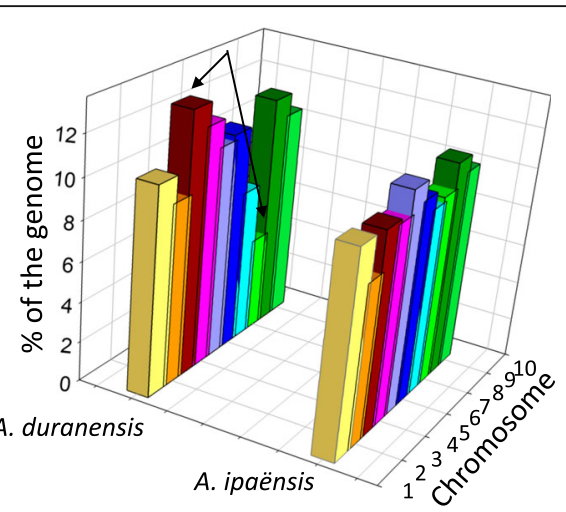

A. ipaënsis

Fig. 1 Left: Percentage of markers from this study, found in the same corresponding chromosomes of A. ipaënsis and A. duranensis (total 193 markers), and their distribution by chromosome. Right: Size of each of the 10 chromosomes of A. ipaënsis and A. duranensis, in proportion to their entire genomes. Arrows indicate the larger size of chromosome three and smaller size of chromosome eight in A. duranensis. Chr: chromosome

obtained from the literature, [21, 39-43], a list is summarized in Additional file 2: Table S2. Only few markers were detected only in the A or B genomes using BLAST analysis on $A$. duranensis and A. ipaënsis, these were NPRL_contig00098a (only A), and NPRL_contig00139a and NPRL_contig02833a (only B).

Out of 373 markers tested, only two (0.5\%), [NPRL_contig00139a (this work) and AHBGSI1002D05 [41]], were monomorphic and amplified in all 20 wild peanut species; another 10 markers had single amplicons but presented null alleles in one or more samples, therefore were not considered monomorphic (Additional file 1: Table S1). From the 325 markers that resulted in amplification, the total number of alleles observed was 2473, the number of alleles per marker ranged between 2 and 26 , with an average of 7.7 alleles per locus, data shown in Additional file 1: Table S1. A total of 130 markers tested, either failed to amplify some of the samples, presented multiple amplicons with stutters, or had very low fluorescence in one or more samples; another 109 markers amplified in all the samples but were not easy to score, thus, these 239 (130 +109) markers were excluded from the multivariate analysis. The remaining 134 markers (104 from this work, and 30 from the literature) were transferable across all 20 accessions of wild peanuts, had no null alleles, had good levels of fluorescence and were easy to score. These 134 markers were used in cluster analysis by Neighbor-Joining (NJ), as well as in Principal Component Analysis (PCA) and 3D-Principal Coordinate Analysis (3D-PCoA).

Cluster analysis by NJ, separated the wild peanut accessions into five main groups mostly according to their genome types reported in the literature; thus, the group with the dark-blue symbol corresponded in general to A genome, pink symbol grouped mostly E genome, green symbol was represented by the $\mathrm{H}$ genome, grey symbol grouped the K genome, and light-blue included B D and F genomes, Fig. 2. Similar results were observed for
PCA, the first three components explained $16 \%, 11 \%$ and $9 \%$ (total $36 \%$ ) of the genetic variation, and data are plotted for components PCA1 and PCA2 in Fig. 3. The results of 3D-PCoA largely corresponded to those obtained through NJ cluster analysis and PCA, though a more clear definition of groups was observed for the first three coordinates, which explained 34\%, 25\%, and $21 \%$ (total $80 \%$ ) of the genetic variation, Fig. 3. Similar colors were used for the graphics of NJ, PCA and 3D-PCoA to reflect the consistency of grouping patterns obtained by different analyses. The group formed by B D F genome (light blue symbol) was close to Arachis batizocoi (Krapovickas \& Gregory) and Arachis cruziana (Krapovickas, Gregory \& Simpson) K genome (grey symbol) both in $\mathrm{PCA}$ and PCoA; in NJ the B D F genome group was slightly more distant from the $\mathrm{K}$ genome group, though in this case the confidence level for this clade was relatively low, only $56.8 \%$, Fig. 2 . A total of 98 high-quality markers that discriminated genomes (e.g., $\mathrm{H}, \mathrm{D}, \mathrm{F}, \mathrm{AB}, \mathrm{E}$, $\mathrm{R} 1, \mathrm{R} 2)$ or groups of genomes (e.g., $\mathrm{E}+\mathrm{R} 2, \mathrm{~B}+\mathrm{F}, \mathrm{D}+\mathrm{H})$ were organized by their quality (from excellent to doable) and are listed in Additional file 4: Table S4. The top four markers with highest discrimination power showed no hits on BLAST2GO analysis.

Unexpected results were observed for two of the samples, Arachis benthamii (Handro) (PI 468162) and Arachis correntina (Burkart) Krapovickas \& Gregory (PI 210554). The latter should have been placed by the analyses with the A genome (dark-blue group), but was co-located with the group of $\mathrm{E}$ genome; whereas $A$. benthamii which should have been with the E genome (pink group), was instead grouped with the A genome. Marker fingerprinting of a second sample from the same seed shipment of seed labeled as A. correntina (PI 210554) gave the same results. A third fingerprinting of seed labeled as A. correntina (PI 210554) performed using seeds from a second shipment from the germplasm collection eight months later and 


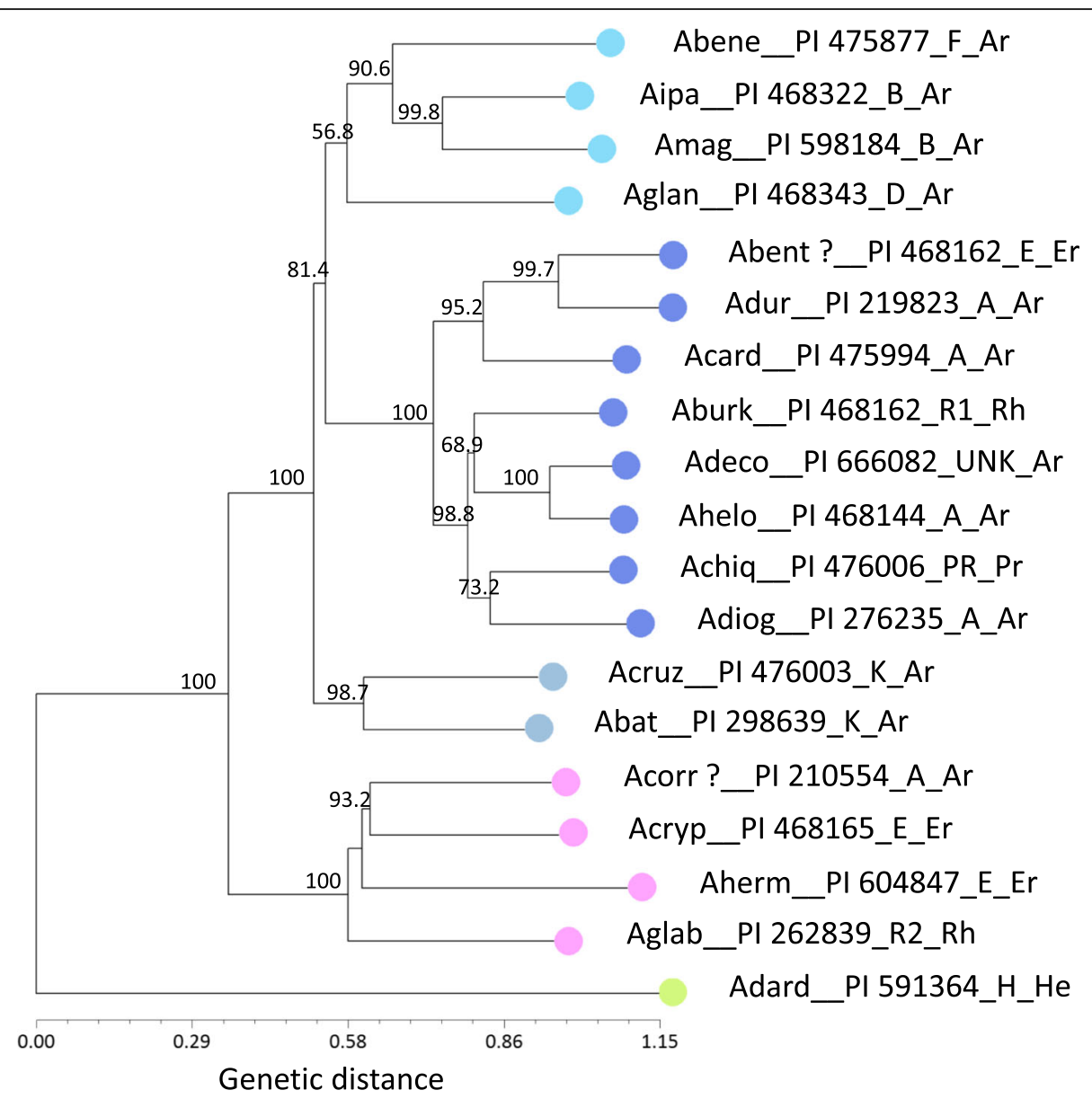

Fig. 2 Neighbor-joining dendrogram based on Nei's standard genetic distance using 134 molecular markers on 20 wild species of peanut. The samples are colored to indicate the overall grouping of species by genome type (dark blue: A, pink: E, grey: K, green: H, light blue: B D F). The same colors were used for each sample in PCA and 3D-PCoA analyses. Only bootstrap values higher than 50 are shown at the nodes. For graphic clarity the species names were shortened, please see List of Abbreviations. Species names are followed by PI, genome type and Section (Ar: Arachis; Er: Erectoides; He: Heteranthae; Pr: Procumbentes; Rh: Rhizomatosae). 98 good-quality markers that discriminated genomes follow the same color code in Additional file 4: Table S4

followed by new analyses by NJ, PCA and 3D-PCoA, showed results similar to the first two fingerprinting. The results for new seed of $A$. benthamii obtained from the bank of germplasm were also similar to the first fingerprinting. Photographs taken from two plants labeled as $A$. correntina (PI 210554) growing at the germplasm collection in Griffin, showed semi-erect or erect stems, had long leaflets and long rachis similar to the appearance of plants in section Erectoides, and not typical characteristics of the species $A$. correntina. A. benthamii was not currently being grown in the germplasm collection.

One of the goals of this work was to provide molecular tools that can help identify germplasm in the peanut collection, and that can be used for accurate identification of each accession when screened for agronomic traits, e.g., resistance to aflatoxin accumulation. The initial list of 134 good quality markers was further condensed to keep only those with high levels of fluorescence and minimum or no background amplification, in addition to being polymorphic. This new set was comprised of 88 markers, including 71 from the present work and 17 from the literature. For these 88 markers we ran the script UPIC that provides the number of samples discriminated by each marker (UPIC score) and the combination of the minimum number of markers necessary to identify each of the samples tested. The UPIC scores for the best 88 markers are listed in Table 2; and the discrimination of all 20 accessions of wild peanut was accomplished by a combination of three new SSR markers: NPRL_cont01020a, NPRL_cont00528b and NPRL_BVZOG. Electropherogram results for marker NPRL_cont01020a (UPIC score: 16) are shown in Fig. 4. Among the 88 markers, 45 had DNA sequences with significant hits in BLAST2GO, these were related to: Transcription factors (5); Growth regulation (4); Signal Transduction (4); Sugar metabolism (4); Transport (4); Apoptosis (2); ATP receptor/synthesis (2); 

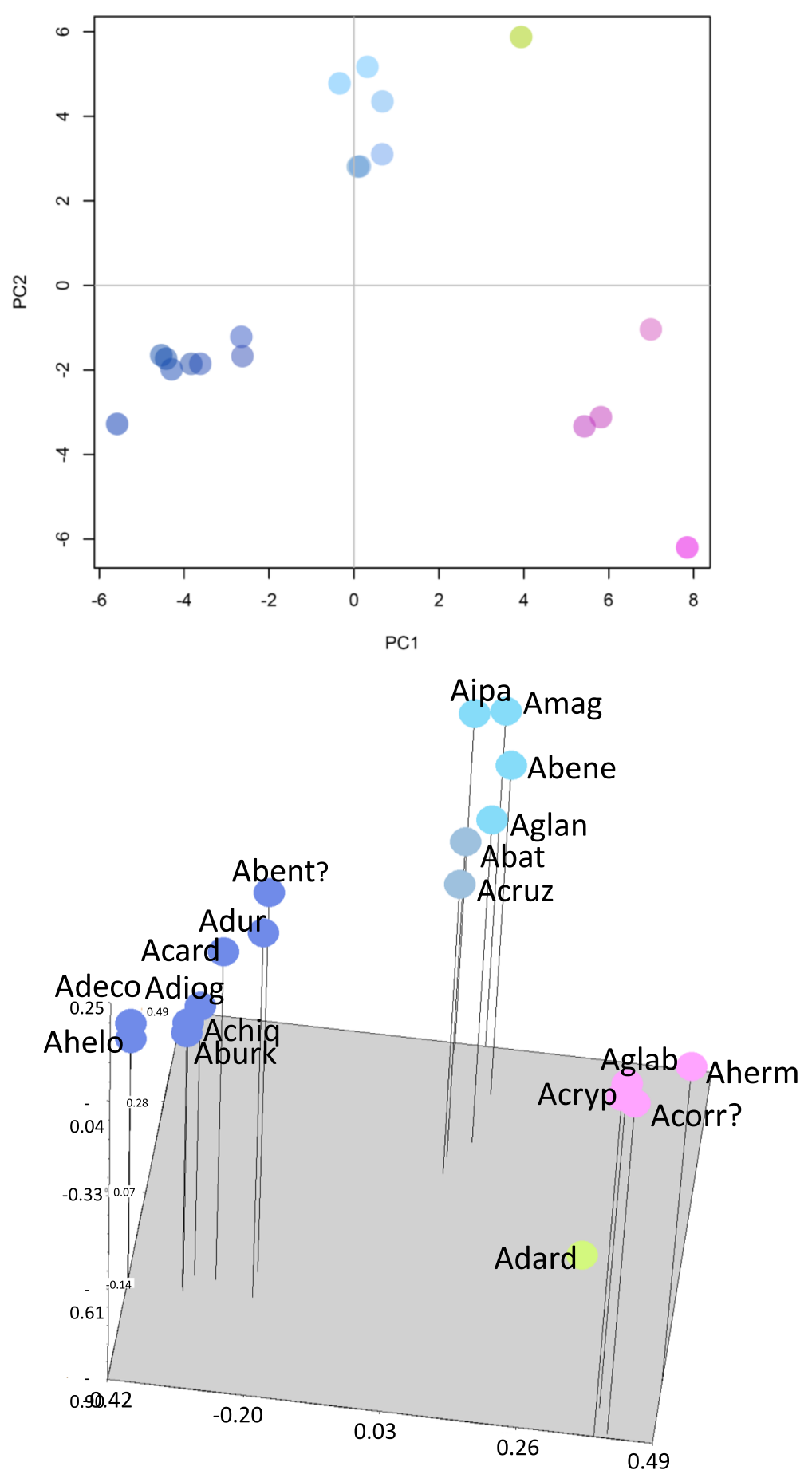

Fig. 3 Graph of the first two axes from a principal component analysis (PCA) (Top) and 3-Dimention-Principal Coordinate Analysis (3D-PCoA) (Bottom) of 20 wild species of peanut using 134 molecular markers (including SSRs and InDels). The first component explains $16 \%$ and the second $11 \%$ of the total genetic variation; and the first 3 PCoA dimensions explained $34 \%, 25 \%$ and $21 \%$ (total $80 \%$ ) of the genetic variation. For graphic clarity the species names were shortened, please see List of Abbreviations. Color code as in Fig. 2

Embryogenesis (2); Organelle coat protein/receptor (2); Chloroplast synthesis (1); Glycosylation (1); Metabolic enzymes (1); Metal tolerance (1); Oligo transporter (1); Pentatricopeptide (1); Stress response (1); Translation (1); results are shown in Additional file 1: Table S1. The UPIC script was used to calculate heterozygosity of the samples at 134 loci, using the fingerprinting results of markers that amplified all the samples. Presence of two or more 
Table 2 List of polymorphic and high quality markers (SSRs and InDels) screened with UPIC scripts. UPIC scores are the number of species with unique allele patterns out of 20 species tested

\begin{tabular}{lllllllll}
\hline Marker & UPIC & Marker & UPIC & Marker & UPIC & Marker & UPIC & Marker \\
& score & & score & & score & & UPIC \\
score
\end{tabular}

amplicons in a sample at one locus was considered heterozygous. The highest levels of heterozygosity observed were $66 \%, 61 \%$ and $50 \%$, and corresponded to Arachis monticola Krapovickas \& Rigoni, Arachis glabrata Benth. (Harms ex Kuntze) Herm and Arachis chiquitana Krapovickas, Gregory \& Simpson; the first two are tetraploids while the third one is a diploid. The lowest heterozygosity was observed in Arachis magna Krapov. et al. with only 6 $\%$ of heterozygous loci, Fig. 5. The heterozygosity level for the rest of the samples ranged from $10 \%$ to $23 \%$.

A second goal of this work was to screen the 20 wild species of peanut for aflatoxin accumulation using a method developed at the NPRL [27]. This method consists of challenging surface-sterilized half seeds with the application of spores of Aspergillus flavus NRRL 3357, followed by incubation and subsequent analysis of aflatoxins $B_{1}$ and $\mathrm{B}_{2}$ using UPLC. No correlation was observed between the mass of Aspergillus mycelium or spores and the concentration of aflatoxins in the seeds. The small sample size used in this method, half cotyledon, was thought suitable for the limited supply of seeds available from the germplasm collections. Given the small size of the seeds for the present work, several modifications were made to the original protocol, and are described in the methods section. A critical new addition to the method was the test of viability through germination (in test tube) of each seed being challenged with the aflatoxigenic fungus. Half seeds containing the embryonic axis and placed in test tubes with Hoagland's medium, were considered viable if the radicle emerged from the seed. Aflatoxin content quantified only from challenged "half seeds" that had a corresponding viable half were reported here. Only 16 of the 20 wild species of peanut showed viability, nine of them had no detectable levels of aflatoxins $B_{1}$ and $B_{2}$, the other seven wild species and the control (Georgia-G11J) showed accumulation of aflatoxin $B_{1}$ between 7 and 19351 ng.g ${ }^{-1}$ seed, and $B_{2}$ between 0.25 and 155 ng.g $^{-1}$ seed. Data were converted to $\log _{10}(x+1)$, and their mean and standard errors plotted, Fig. 6. Mean comparisons of the transformed values of aflatoxin $B_{1}$ by all combinations of paired T-tests showed three groups significantly different ( $\mathrm{p} \leq 0.05$ ), Fig. 6. Similar comparisons performed for the content of aflatoxin $\mathrm{B}_{2}$ detected only two different groups ( $p \leq$ 0.05). Both aflatoxins, $B_{1}$ and $B_{2}$ were highest on Georgia-11J and on the sample received from the collection as A. correntina (PI 210554). Neither, aflatoxin $\mathrm{B}_{1}$ nor $\mathrm{B}_{2}$, were detected in Arachis benensis, A. benthamii, Arachis burkatii, Arachis chiquitana, Arachis dardani, Arachis decora, A. duranensis, Arachis glandulifera and Arachis hermannii, Fig. 6.

\section{Discussion}

Improved tools are presented here, for the systematic screening of the small-size seeds of wild peanut species from germplasm collections to search for aflatoxin resistance; this approach uses single seed analysis, takes into 


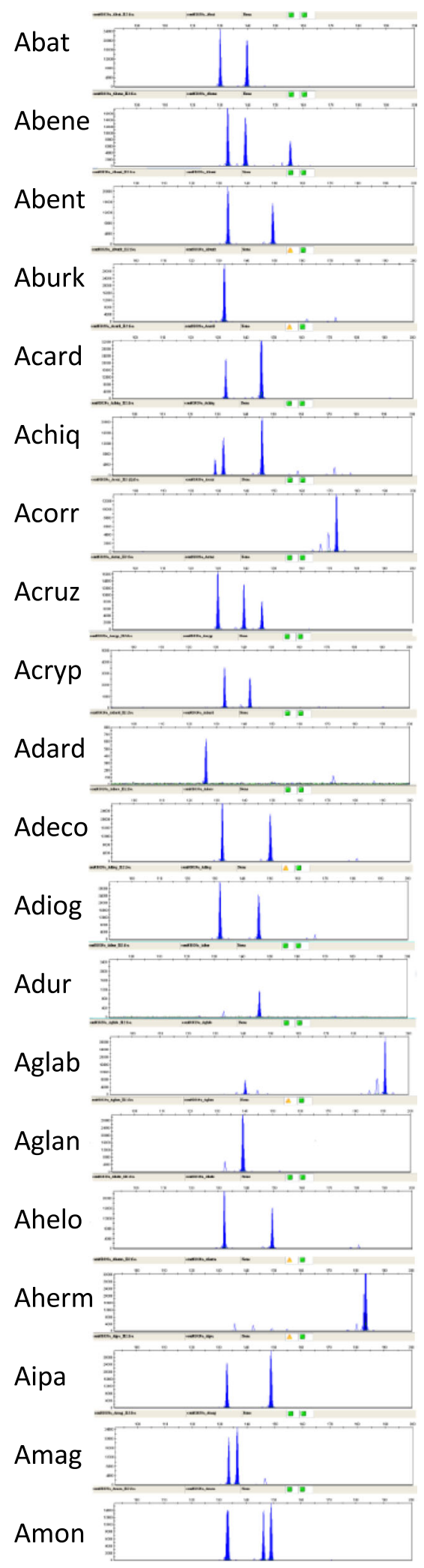

Fig. 4 Electropherogram of amplicons generated on 20 wild peanut species using marker NPRL cont01020a, this primer had UPIC score 16 , that means 16 allele patterns were observed. $X$ axis is in base pairs, and $Y$ axis is fluorescence level. For graphic clarity the species names were shortened, please see List of Abbreviations

consideration the seed viability and keeps record of the genetic fingerprinting of each accession. The complex genetics of aflatoxin resistance in peanut [24], combined with the large sample size required to reduce the variability of aflatoxin contamination data obtained in field experiments [26], have hindered the search of aflatoxin resistance as a trait. A significant reduction in sample size, and successful screening had been achieved using only $5 \mathrm{~g}$ of seeds per replicate, inoculated with Aspergillus flavus to detect aflatoxin resistance [6]. However, for the small size of wild peanut seeds, $5 \mathrm{~g}$ (in shell) would represent 36 seeds of $A$. batizocoi and 45 seeds of $A$. dardani, two species used in the present study; these are still very large numbers considering their limited supply. Thus, using single seeds per replicate as proposed here is a more suitable approach, and it allowed for statistical comparisons. Seed viability can be compromised by long term storage of peanut in banks of germplasm [53]. Thus, crucial to the protocol, is the testing of viability, which validates aflatoxin quantification as a result of the interaction between a live seed and the fungal pathogen. The results in Fig. 6, showed nine species with aflatoxin $B_{1}$ and $B_{2}$ below the minimum detection limit of the assay $\left(0.10 \mathrm{ng} \cdot \mathrm{g}^{-1} \mathrm{~B}_{1}\right.$; and $0.01 \mathrm{ng} \cdot \mathrm{g}^{-1}$ for aflatoxin $\left.\mathrm{B}_{2}\right)$. Overall, individuals with genomes $\mathrm{A}, \mathrm{B}$ and $\mathrm{K}$ showed more accumulation of aflatoxins than those with genomes R1, $\mathrm{PR}, \mathrm{H}$ and F. Though this study does not claim that the eight peanut species showing aflatoxin accumulation are susceptible, there is a higher probability of low or no resistance in accessions that accumulated aflatoxin; the experiment could be repeated to confirm potential candidates before their use in breeding programs. The same accessions of $A$. duranensis and A. cardenasii that here showed significant differences in aflatoxin accumulation had been reported with overall low levels of aflatoxin accumulation by Xue et al. 2004 in in vitro assays [6]. In that work, A. cardenasii had only $16-32 \%$ the level of aflatoxin observed in $A$. hypogaea controls, and A. duranensis had between 12-24 \% the level found in the controls. In our study A. cardenasii had $30 \%$ of the level of aflatoxin in the control and $A$. duranensis had $0 \%$. To account for potential genetic variations within accessions of wild peanut species, we believe the genetic fingerprinting will help explain this type of variation.

In the present work, cluster analysis by Neighbor-Joining, PCA and 3D-PCoA were done for the purpose of visualizing the potential use of the markers in finding association between accessions according to their genomes described in the literature, and to keep record of the genetic 


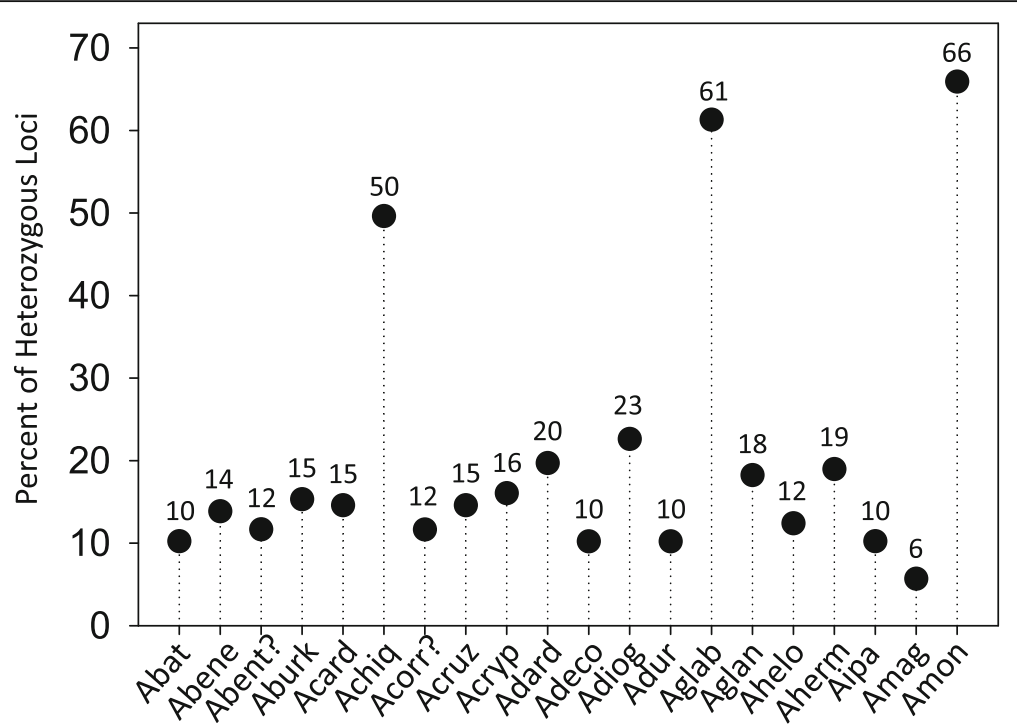

Fig. 5 Percentage of heterozygous loci observed on 20 wild peanut species using 134 molecular markers that were transferable to all the species. For graphic clarity the species names were shortened, please see List of Abbreviations

fingerprinting of the samples. Markers NPRL_cont00626a, NPRL_cont01787a, NPRL_00179a and NPRL_cont00098a, discriminated 6, 4, 4, and 3 genomes, respectively; a total of 98 genome-discriminating markers are provided in Additional file 4: Table S4. In a study using 67 SSRs, Moretzsohn et al. (2004) found that accessions containing the same genome type tend to group together [43]; similar grouping according to genomes was also observed when intron sequences of single-copy genes were used to create a phylogenetic tree of multiple peanut species and accessions [54]. Given the high transferability across species for the markers reported in the present work, the high support by bootstrap (5000 replicates) observed on the dendrogram clades, Fig. 2, and the distinct groups observed in PCA and 3D-PCoA analyses, the grouping of the samples by genome seems to be clear. However, two samples were apparently misplaced; these were $A$. benthamii (PI 468162) that grouped with section Arachis group, and A. correntina (PI

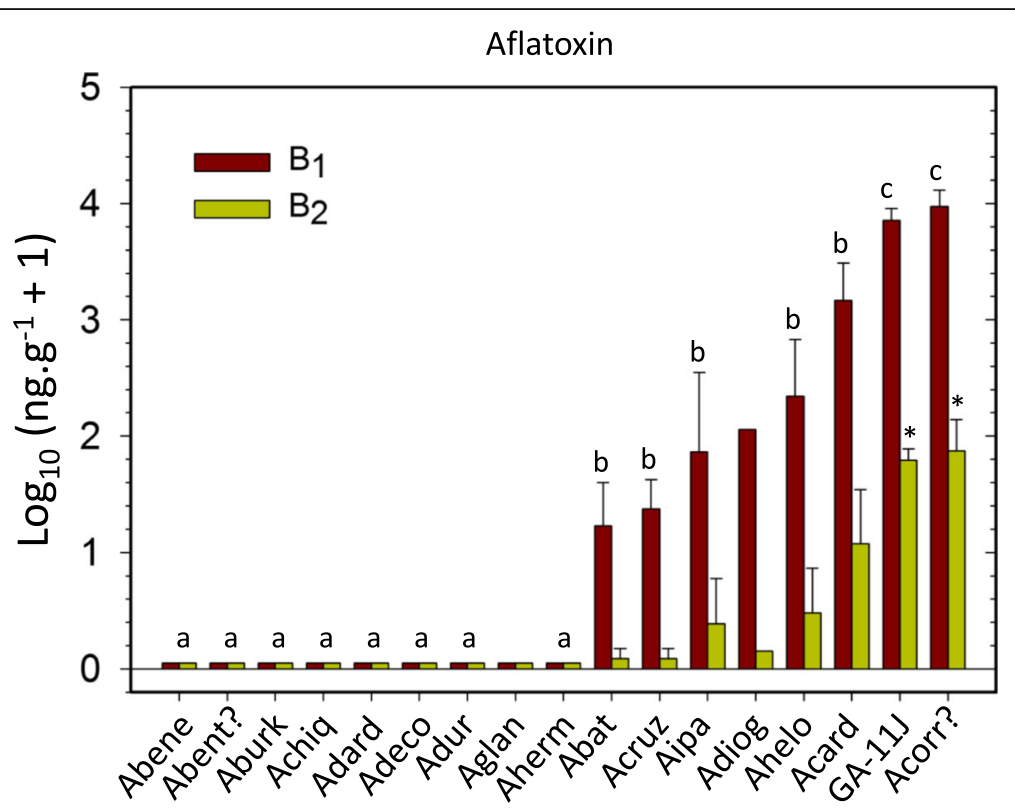

Fig. 6 Concentration of aflatoxin $B_{1}$ and $B_{2}$ detected on individual seeds of 16 wild peanut species. Only 16, out of 20 species tested shown viability in in vitro culture, therefore were used in the analysis. Same letters indicate samples not significantly different from each other; samples without letters were not included in the statistical analysis. For graphic clarity the species names were shortened, please see List of Abbreviations 
210554) was placed with section Erectoides group. The PI 210554 has been extensively studied for decades, given its characteristic multiple disease resistance, and it was sometimes reported with different identification, for example as A. villosa ICG 8144 [55], A. villosa (PI 210554) [56], A. villosa (PI 210554) [57], A. villosa ICG 8144 [58], and as Arachis accession PI 210554 [59]. This prompted us to repeat the 373-marker fingerprinting of additional samples of PI 210554 received from the germplasm collection on different dates; and each time we obtained the same results, grouping PI 210554 with Erectoides samples instead of section Arachis group. It is possible, that at some point in time an error may have happened in the labeling of these two samples within the collection. The morphology of the plant growing at the germplasm collection was in concordance with the results of multivariate analysis of genetic fingerprinting, grouping it with Erectoides. The process of maintaining viable plant material of thousands of accessions is labor intensive and errors may occur; for example in the germplasm bank of avocado, up to $7 \%$ of loss identification has been reported [60]. The particularly high discrimination of the markers from the present work could be implemented as a resource for a cost-effective screening of the peanut germplasm collection. The placement of A. burkatii (2x) far from A. glabrata (4x) (section Rhizomatosae) is in accordance with the recent cytogenetic report by Ortiz et al (2017)[61] and ITS based phylogenetic analysis [62].

BLAST2GO analysis showed significant hits on 45 of the 88 best markers listed in Table 2. Polymorphism of SSR or InDel markers that showed hits on BLAST2GO, could result in amino acid changes within those proteins and therefore different phenotypes. Thus, the 45 markers with hits on transcription factors, stress response, signal transduction and growth regulation, could be valuable information for pre-breeding programs. We applied UPIC scripts, which is a decision tool for the cost-effective planning of experiments using fingerprinting [52], Table 2, and identified three markers which combined were able to discriminate all 20 wild peanut species. One of these three was NPRL_cont01020a, shown in Fig. 4, which had homology to a pentatricopeptide repeat-containing mitochondrial protein, such RNA-binding proteins regulate gene expression at the post-transcriptional level through RNA processing, splicing, stability, editing and translation, reviewed by Manna (2015) [63]. A second marker, NPRL_cont_00528b, had homology to another RNA-binding protein, the La-related protein LARP-1B, involved in the M-phase of the cell cycle in Arachis duranensis; LARP-1B homologs may function generally to control the expression of key developmental regulators in Caenorhabditis elegans [64], and in eukaryotes in general, binding transcripts of RNA Polymerase III [65]. The third marker in the group was NPRL_BVZOG, which in BLAST2GO showed homology to UDP-D-apiose/ UDP-D-xylose synthase 1-like; mutations in this enzyme reduce apiose synthesis, thus preventing the cross-linking of rhamnogalacturonan II, and therefore the integrity of the plant cell wall [66]. Since the plant cell wall is the first barrier of protection against pathogens [67], the polymorphism of marker NPRL_BVZOG would be worth of further consideration. Overall, $92 \%$ of the markers reported here, had only two hits or less (E $10^{-5}$ ) per $\mathrm{A}$ or $\mathrm{B}$ genome (A. duranensis and $A$. ipaënsis). The few markers that showed more than two hits per genome, or high copy number, are highlighted in yellow in Additional file 1: Table S1.

Heterozygosity shown in Fig. 5, matches the trends expected by ploidy level, for example, $A$. monticola is 2 n: $40[20,68]$, and had $66 \%$; A. glabrata the only tetraploid species known outside section Arachis, has 2n: 40 [69, 70] and presented a $61 \%$ heterozygosity. A. chiquitana was the only species that showed higher heterozygosity (50\%) than expected. This species is listed as $2 n=2 x=20$; however, it has a satellite greater than the sum of arm 1 and arm 2 [71]. This may explain the higher level of heterozygosity observed for this species. Phylogenetic anomalies have been observed on the SSR fingerprinting of three A. chiquitana accessions, where one accession clustered together with $A$. diogoi and another accession was distant from the rest [72]. This emphasizes the need of keeping a genetic fingerprinting record of accessions being tested.

\section{Conclusions}

A set of cost-effective tools was developed to screen the small-size wild peanut seeds for aflatoxins. The method uses single seed analysis, considering potential loss of viability in storage, and keeping record of the genetic fingerprinting of each accession. A large new set of microsatellites and a combination of highly informative markers for screening are reported.

\section{Additional files}

Additional file 1: TableS1. BLAST results for 345 DNA sequences from which the markers were designed, using the Arachis duranensis and Arachis ipaënsis genomes as databases. (XLSX $106 \mathrm{~kb}$ )

Additional file 2: Table S2. Primer sequences of the 288 SSRs developed in the present work. Number of alleles detected per marker, range of amplicon size, and BLAST2GO results for the sequences are also included. (XLSX 29 kb)

Additional file 3: Table S3. List of markers, InDels and SSRs used from the literature. (XLSX $34 \mathrm{~kb}$ )

Additional file 4: Table S4. Discrimination of genomes (e.g., H, D, F, AB, $E, R 1, R 2$ ) or groups of genomes (e.g., $E+R 2, B+F, D+H)$ by 98 markers organized by their quality (from excellent to doable). Genomes that were discriminated by a marker as group, were indicated with a " + " sign in between, e.g., F+D. Some cell colors correspond to the ones used in Fig. 2 and 3. (XLSX 32 kb) 


\section{Abbreviations}

Abat: Arachis batizocoi; Abene: Arachis benensis; Abent: Arachis benthamii; Aburk: Arachis burkatii; Acard: Arachis cardenasii; Achiq: Arachis chiquitana; Acorr?: Arachis correntina?; Acruz: Arachis cruziana; Acryp: Arachis cryptopotamica; Adard: Arachis dardani; Adeco: Arachis decora; Adiog: Arachis diogoi; Adur: Arachis duranensis; Aglab: Arachis glabrata; Aglan: Arachis glandulifera; Ahelo: Arachis helodes; Aherm: Arachis hermanii; Aipa: Arachis ipaënsis; Amag: Arachis magna; Amont: Arachis monticola; 3D-PCoA: 3-D Principal Coordinate Analysis; BLAST: Basic Local Alignment Search Tool; BLAST2GO: BLAST to Gene Ontology; InDel: Insertion Deletion; IVSC: In Vitro seed colonization; NJ: Neighbor Joining; NPRL: National Peanut Research Laboratory; PCA: Principal Component Analysis; PGRCU: PI. Genetic Res. Conservation Unit; SSR: Simple sequence repeat; UPIC: Unique Pattern Informative Combinations; UPLC: Ultra-performance liquid chromatography

\section{Funding}

This project was supported by USDA-ARS projects: NP301 6604-21000-004-00D and NP303 6604-42000-008-00D, financial support only.

\section{Availability of data and materials}

Supporting data and sources used for this manuscript are provided in Additional file 1: Tables S1, Additional file 2: Tables S2, Additional file 1: Tables S3 and Additional file 1: Tables S4. Electropherograms generated in this work (approximately 200 Mbytes of data) are available from the corresponding author on reasonable request.

\section{Authors' contributions}

RA, VS and TW carried out most of the experiments. RA, VS, AM, LB analyzed the data. SS, VO, FB, TW extracted, organized and curated the data and photographs. NP and BS provided seed material, contributed to data generation and supervised bioinformatics. GS provided crucial information for the design of experiments. RA and VS wrote the manuscript. All authors read, revised and approved the final manuscript.

\section{Ethics approval and consent to participate}

Not applicable.

\section{Consent for publication}

Not applicable.

\section{Competing interests}

The authors declare that they have no competing interests.

\section{Publisher's Note}

Springer Nature remains neutral with regard to jurisdictional claims in published maps and institutional affiliations.

\section{Author details \\ 'USDA-ARS-NPRL, National Peanut Research Laboratory (NPRL), 1011 Forrester Dr. S.E, Dawson, GA 39842, USA. ${ }^{2}$ USDA-ARS-GBRU, Genomics and Bioinformatics Research Unit, 141 Experiment Station rd, Stoneville, MS 38776, USA. ${ }^{3}$ New Mexico State University, Agricultural Science Center at Clovis, 2346 SR 288, Clovis, NM 88101, USA. ${ }^{4}$ Facultad de Ciencias Exactas y Naturales y Agrimensura, Universidad Nacional del Nordeste, Av. Libertad 5470, C.P, 3400 Corrientes, Argentina. ${ }^{5}$ Instituto de Botánica del Nordeste, (UNNE-CONICET), Casilla de Correo 209, 3400 Corrientes, Argentina.}

\section{Received: 29 September 2017 Accepted: 19 June 2018}

\section{Published online: 15 August 2018}

\section{References}

1. Blount WP. Turkey "X" disease. Turkeys. 1961;9:52-7.

2. Mehan V, McDonald D, Ramakrishna N, Williams J. Effect of cultivar and date of harvest on infection of peanut seed by Aspergillus flavus and subsequent contamination with aflatoxin. Peanut Science. 1986;13:46-50.

3. Rao MJV, Upadhyaya HD, Mehan VK, Nigam SN, Mcdonald D, Reddy NS. Registration of Peanut Germplasm Icgv-88145 and Icgv-89104 Resistant to Seed Infection by Aspergillus flavus. Crop Science. 1995;35(6):1717-7.
4. Holbrook CC, Wilson DM, Matheron ME, Hunter JE, Knauft DA, Gorbet DW Aspergillus colonization and aflatoxin contamination in peanut genotypes with reduced linoleic acid composition. Plant Dis. 2000;84(2):148-50.

5. Waliyar F, Kumar KVK, Diallo M, Traore A, Mangala UN, Upadhyaya HD, Sudini $H$. Resistance to pre-harvest aflatoxin contamination in ICRISAT's groundnut mini core collection. European J Plant Pathology. 2016; 145(4):901-13.

6. Xue HQ, Isleib TG, Stalker HT, Payne GA, O'Brien G. Evaluation of Arachis Species and Interspecific Tetraploid Lines for Resistance to Aflatoxin Production by Aspergillus flavus. Peanut Science. 2004;31(2):134-41.

7. AACR: American Association for Cancer Research. An Evaluation of Chemicals and Industrial Processes Associated with Cancer in Humans Based on Human and Animal Data: IARC Monographs Volumes 1 to 20. Cancer Research. 1980;40(1):1-12

8. Eaton DL, Groopman JD. The toxicology of aflatoxins: human health, veterinary, and agricultural significance. San Diego: Academic Press; 1994.

9. Pier AC, Fichtner RE, Cysewski SJ. Effects of aflatoxin on the cellular immune system. Ann Nutr Aliment. 1977;31((4-6)):781-8.

10. Lamb MC, Sternitzke DA. Cost of aflatoxin to the farmer, buying point, and sheller segments of the Southeast United States peanut industry. Peanut Science. 2001;28:59-63.

11. Leidner J. The peanut genomics initiative. Southestern Peanut Farmer. 2012; 50:15.

12. Wu F, Liu Y, Bhatnagar D. Cost-Effectiveness of Aflatoxin Control Methods: Economic Incentives. Toxin Reviews. 2008;27(3-4):203-25.

13. Kochert G, Stalker HT, Gimenes M, Galgaro L, Lopes CR, Moore K. RFLP and cytogenetic evidence on the origin and evolution of allotetraploid domesticated peanut, Arachis hypogaea (Leguminosae). Am J Bot. 1996; 83(10):1282-91.

14. Mallikarjuna N, Senthilvel S, Hoisington D. Development of new sources of tetraploid Arachis to broaden the genetic base of cultivated groundnut (Arachis hypogaea L.). Genetic Resources and Crop Evolution. 2011;58:889-907.

15. Yuan M, Gong LM, Meng RH, Li SL, Dang P, Guo BZ, He GH. Development of trinucleotide (GGC)n SSR markers in peanut (Arachis hypogaea L.) Electron J Biotechn. 2010;13(6)

16. Varshney RK, Bertioli DJ, Moretzsohn MC, Vadez V, Krishnamurthy L, Aruna R, Nigam SN, Moss BJ, Seetha K, Ravi K, et al. The first SSR-based genetic linkage map for cultivated groundnut (Arachis hypogaea L.). Theoretical Applied Genetics. 2009;118(4):729-39.

17. Savadi SB, Fakrudin B, Nadaf HL, Gowda MVC. Transferability of sorghum genic microsatellite markers to peanut. Am J Plant Sci. 2012;3:1169-80.

18. Chopra R, Burow G, Simpson CE, Chagoya J, Mudge J, Burow MD. Transcriptome Sequencing of Diverse Peanut (Arachis) Wild Species and the Cultivated Species Reveals a Wealth of Untapped Genetic Variability. G3Genes Genom Genet. 2016;6(12):3825-36.

19. Simpson CE. Plant Exploration: Planning, Organization, and Implementation with Special Emphasis on Arachis,. In: Conservation of Crop Germplasm - An International Perspective. In: Brown TTC WL, Goodman MM, Jones Q, editors. Special Publication Number 8: CSSA, Crop Science Society of America; 1984 p. 1-20.

20. Krapovickas A, Gregory WC. Taxonomia del Genero Arachis (Leguminosae). Bonplandia. 1994;8(1-4):1-186.

21. Proite K, Leal-Bertioli SC, Bertioli DJ, Moretzsohn MC, da Silva FR, Martins NF, Guimarães PM. ESTs from a wild Arachis species for gene discovery and marker development. BMC Plant Biology. 2007;7(1):7.

22. Barkley N, Upadhyaya HD, Liao BS, Holbrook C. Global resources of genetic diversity in peanut. In: Peanuts: Genetics, Processing and Utilization. Editors: Stalker HT and Wilson RF. Champaign: AOCS Press; p. 67-109

23. Valls JFM, Ramanatha Rao V, Simpson CE, Krapovickas A. Current status of collection and conservation of South American groundnut germplasm with emphasis on wild species of Arachis. In: International Workshop, ICRISAT. India: Patancheru, Andhra Pradesh; 1985. p. 15-35.

24. Nigam SN, Waliyar F, Aruna R, Reddy SV, Kumar PL, Craufurd PQ, Diallo AT, Ntare BR, Upadhyaya HD. Breeding peanut for resistance to aflatoxin contamination at ICRISAT. Peanut Science. 2009:36(1):42-9.

25. Whitaker TB. Standardisation of mycotoxin sampling procedures: an urgent necessity. Food Control. 2003;14(4):233-7.

26. Whitaker TB, Dorner JW, Giesbrecht FG, Slate AB. Variability among aflatoxin test results on runner peanuts harvested from small field plots. Peanut Science. 2004;31:59-63. 
27. Arias RS, Dang PM, Sobolev VS. RNAi-mediated control of aflatoxins in peanut: Method to analyze mycotoxin production and transgene expression in the peanut/Aspergillus pathosystem. J Visualized Experiments. 2015:106-e353398.

28. Sobolev VS. Simple, rapid, and inexpensive cleanup method for quantitation of aflatoxins in important agricultural products by HPLC. J Agricultural Food Chemistry. 2007;55(6):2136-41.

29. Sobolev VS, Dorner JW. Cleanup procedure for determination of aflatoxins in major agricultural commodities by liquid chromatography. J Aoac Int. 2002;85(3):642-5.

30. Techen N, Arias RS, Glynn NC, Pan Z, Khan I, Scheffler BE. Optimized construction of microsatellite-enriched libraries. Molecular Ecology Resources. 2010;10:508-15.

31. Glenn TC, Schable NA. Isolating microsatellite DNA loci. Methods in Enzymology. 2005;395:202-22.

32. Hayden MJ, Good G, Sharp PJ. Sequence tagged microsatellite profiling (STMP): improved isolation of DNA sequence flanking target SSRs. Nucleic Acids Res. 2002;30(23):e129

33. Kijas JM, Fowler JC, Garbett CA, Thomas MR. Enrichment of microsatellites from the citrus genome using biotinylated oligonucleotide sequences bound to streptavidin-coated magnetic particles. Biotechniques. 1994;16(4):656-60.

34. Sharopova N, McMullen MD, Schultz L, Schroeder S, Sanchez-Villeda H, Gardiner J, Bergstrom D, Houchins K, Melia-Hancock S, Musket T, et al. Development and mapping of SSR markers for maize. Plant Mol Biol. 2002; 48(5-6):463-81.

35. Rozen S, Skaletsky H. Bioinformatics Methods and Protocols in the series Methods in Molecular Biology. Totowa: Humana Press; 2000.

36. Bertioli DJ, Cannon SB, Froenicke L, Huang G, Farmer AD, Cannon EKS, Liu X, Gao D, Clevenger J, Dash S, et al. The genome sequences of Arachis duranensis and Arachis ipaënsis, the diploid ancestors of cultivated peanut. Nat Genet. 2016;48(4):438-46.

37. Conesa A, Gotz S, Garcia-Gomez JM, Terol J, Talon M, Robles M. Blast2GO: a universal tool for annotation, visualization and analysis in functional genomics research. Bioinformatics. 2005;21(18):3674-6.

38. Branch WD. Registration of 'Georgia-11J' Peanut. J Plant Regist. 2012; 6(3):281-3.

39. Liu L, Dang PM, Chen CY. Development and Utilization of InDel Markers to Identify Peanut (Arachis hypogaea) Disease Resistance. Frontiers in Plant Science. 2015;6(988)

40. Ferguson ME, Burow MD, Schulze SR, Bramel PJ, Paterson AH, Kresovich S, Mitchell S. Microsatellite identification and characterization in peanut (A. hypogaea L.). Theoretical and Applied Genetics. 2004;108(6):1064-70.

41. Leal-Bertioli SC, José ACV, Alves-Freitas DM, Moretzsohn MC, Guimarães PM, Nielen S, Vidigal BS, Pereira RW, Pike J, Fávero AP, et al. Identification of candidate genome regions controlling disease resistance in Arachis. BMC Plant Biology. 2009;9(1):112.

42. Moretzsohn MC, Leoi L, Proite K, Guimarães PM, Leal-Bertioli SCM, Gimenes MA, Martins WS, Valls JFM, Grattapaglia D, Bertioli DJ. A microsatellite-based, gene-rich linkage map for the AA genome of Arachis (Fabaceae). Theoretical and Applied Genetics. 2005;111(6):1060-71.

43. MdC M, Hopkins MS, Mitchell SE, Kresovich S, JFM V, Ferreira ME. Genetic diversity of peanut (Arachis hypogaeaL.) and its wild relatives based on the analysis of hypervariable regions of the genome. BMC Plant Biology. 2004;4(1):11.

44. Guo DL, Luo ZR. Microsatellite isolation and characterization in Japanese persimmon (Diospyros kaki). Biochem Genet. 2008;46(5-6):323-8.

45. Waldbieser GC, Quiniou SM, Karsi A. Rapid development of gene-tagged microsatellite markers from bacterial artificial chromosome clones using anchored TAA repeat primers. Biotechniques. 2003;35(5):976-9.

46. Brownstein MJ, Carpten JD, Smith JR. Modulation of non-templated nucleotide addition by tag DNA polymerase: Primer modifications that facilitate genotyping. Biotechniques. 1996;20(6):1004.

47. Arias RS, Ray JD, Mengistu A, Scheffler BE. Discriminating microsatellites from Macrophomina phaseolina and their potential association to biological functions. Plant Pathology. 2011;60(4):709-18.

48. Jombart $\mathrm{T}$. adegenet: a $\mathrm{R}$ package for the multivariate analysis of genetic markers. Bioinformatics. 2008;24(11):1403-5.

49. R: A language and environment for statistical computing. $R$ foundation for statistical computing, Vienna, Austria [http://www.R-project.org/]

50. Felsenstein J. Confidence-limits on phylogenies - an approach using the bootstrap. Evolution. 1985:39(4):783-91.
51. Efron B, Halloran E, Holmes S. Bootstrap confidence levels for phylogenetic trees. Proc Natl Acad Sci U S A. 1996;93(23):13429-34.

52. Arias RS, Ballard LL, Scheffler BE. UPIC: perl scripts to determine the number of SSR markers to run. Bioinformation. 2009:3:353-61.

53. Kameswara Rao N, Sastry DVSSR, Bramel PJ. Effects of shell and low moisture content on peanut seed longevity. Peanut Science. 2002;29:122-5.

54. Moretzsohn MC, Gouvea EG, Inglis PW, Leal-Bertioli SCM, Valls JFM, Bertioli DJ: A study of the relationships of cultivated peanut (Arachis hypogaea) and its most closely related wild species using intron sequences and microsatellite markers. Ann Bot-London 2013, 111(1):113-126.

55. Mallikarjuna N, Maheedhar G, Chandra S. Genetic diversity among Arachis species based on RAPDs. Indian J Genetics. 2005;65(1):5-8.

56. Mondal S, Badigannavar AM. Peanut rust (Puccinia arachidis Speg.) disease: its background and recent accomplishments towards disease resistance breeding. Protoplasma. 2015;252:1409-20.

57. Subrahmanyam P, Ghanekar AM, Nolt BL, Reddy DVR, McDonald D. Resistance to groundnut diseases in wild Arachis species. In: International Workshop on Cytogenetics of Arachis. Patancheru: ICRISAT; 1983.

58. Upadhyaya HD, Dwivedi SL, Nadaf HL, Singh S. Phenotypic diversity and identification of wild Arachis accessions with useful agronomic and nutritional traits. Euphytica. 2011;182:103-15.

59. Wang ML, Barkley N, Chinnan M, Stalker HT. Oil content and fatty acid composition variability in wild peanut species. Plant Genetic Resources: Characterization and Utilization. 2010;8(3):232-4.

60. Schnell RJ, Brown JS, Olano CT, Power EJ, Krol CA, Kuhn DN, Motamayor JC. Evaluation of avocado germplasm using microsatellite markers. J Am Soc Hortic Sci. 2003;128(6):881-9.

61. Ortiz AM, Robledo G, Seijo G, Valls JFM, Lavia Gl. Cytogenetic evidences on the evolutionary relationships between the tetraploids of the section Rhizomatosae and related diploid species (Arachis Leguminosae). J Plant Research. 2017;130(791-807)

62. Friend SA, Quandt D, Tallury SP, Stalker HT, Hilu KW. Species, genomes, and section relationships in the genus Arachis (Fabaceae): a molecular phylogeny. Plant Syst Evol. 2010;290(1-4):185-99.

63. Manna S. An overview of pentatricopeptide repeat proteins and their applications. Biochimie. 2015;113:93-9.

64. Nykamp K, Lee MH, Kimble J. C-elegans La-related protein, LARP-1, localizes to germline $\mathrm{P}$ bodies and attenuates Ras-MAPK signaling during oogenesis. Rna. 2008;14(7):1378-89.

65. Bousquet-Antonelli C, Deragon JM. A comprehensive analysis of the La-motif protein superfamily. Rna. 2009;15(5):750-64.

66. Ahn JW, Verma R, Kim M, Lee JY, Kim YK, Bang JW, Reiter WD, Pai HS. Depletion of UDP-D-apiose/UDP-D-xylose synthases results in rhamnogalacturonan-II deficiency, cell wall thickening, and cell death in higher plants. J Biol Chem. 2006;281(19):13708-16.

67. Smirnova OG, Kochetov AV. Plant cell wall and mechanisms of resistance to pathogens. Russ J Genet+. 2016;6(5):622-31.

68. Krapovickas A, Rigoni A. Nuevas especies de Arachis vinculadas al origen de maní. Darwiniana. 1957;11:431-58.

69. Mallikarjuna N. Gene introgression from Arachis glabrata into A. hypogaea, A. duranensis and A. diogoi. Euphytica. 2002;124(1):99-105.

70. Gregory WC. Peanut program underway. Research and Animal Farming. 1946:5:287-90

71. Lavia Gl. Chromosome studies in wild Arachis (Leguminosae). Caryologia. 2000:53(3-4):277-81.

72. Mallikarjuna N, Jadhav D, Chandra S, Prasanth VP: Molecular genetic relationships among Arachis diogoi and A. chiquitana accessions. In. Edited by ICRISAT, vol. 3(1); 2007: 3. 